\title{
Clinical Benefits of Facial Nerve Monitoring during Cerebellopontine Angle Surgery
}

\author{
Ahmed A. Farag1* ${ }^{*}$ Abd El-Kafy Sharaf El-Din Ibrahim², Islam M. Alaghory ${ }^{2}$ \\ ${ }^{1}$ Neurosurgery Department, Shebien Elkom Neurosurgery Hospital, Menufyia, Egypt \\ ${ }^{2}$ Neurosurgery Department, Faculty of Medicine, Al-Azhar University, Cairo, Egypt \\ Email: *Adelns@outlook.com
}

How to cite this paper: Farag, A.A., Ibrahim, A.E.-K.S.E.-D. and Alaghory, I.M. (2022) Clinical Benefits of Facial Nerve Monitoring during Cerebellopontine Angle Surgery. Open Journal of Modern Neurosurgery, 12, 9-27.

https://doi.org/10.4236/ojmn.2022.121002

Received: September 29, 2021

Accepted: December 6, 2021

Published: December 9, 2021

Copyright (C) 2022 by author(s) and Scientific Research Publishing Inc. This work is licensed under the Creative Commons Attribution International License (CC BY 4.0).

http://creativecommons.org/licenses/by/4.0/

\begin{abstract}
Background: The surgery of cerebellopontine angle tumours has remarkably progressed over the last 2 decades due to improved microsurgical techniques. The primary operative goals are microscopic total removal of the tumour while securing the adjacent cranial nerves. Facial Nerve plays a critical role in facial muscles function and one's cosmetic appearance, and its weakness can have profound implications on a patient's quality of life. Aim of the Study: To assess the impact of monitoring techniques on the preservation of facial nerve function during cerebellopontine angle tumours surgery. Patients and Methods: This is a prospective study. This study was conducted on 30 cases (2 groups, each had 15 patients) with CPA lesions that had undergone surgical excision of these lesions performed by retrosigmoid approach (Group A: the patients were operated under continuous intraoperative facial nerve monitoring (IOFNM) and Group B: the patients were operated without IOFNM). They were operated upon in neurosurgery departments at Al-Azhar university hospitals between August 2019 and August 2021. Results: This study showed that excellent facial nerve function (HB Grade I and II) was higher in group A than group B, immediately and at 6-month post op (80\% and 93\% VS 53.3\% and 66.7\%). Intermediate (HB Grade III and VI) and Poor (HB Grade V and VI) facial nerve function was higher in group $B$ than group A; both immediately and 6-month postop ( $46.7 \%$ and $33.3 \%$ VS $20 \%$ and $6.6 \%$ ). However, no statistically significant P-Value between both groups. Conclusion: We concluded that IOFNM can help, but cannot guarantee, the preservation of facial nerve. Furthermore, it is merely a technical adjunct and does not replace surgical skills, knowledge of anatomy and experience.
\end{abstract}

\section{Keywords}

Facial Nerve, Monitoring, Cerebellopontine Angle, Retrosigmoid 


\section{Introduction}

In November 1894, Sir Charles Ballance was credited with performing the first successful complete surgical removal of a CPA tumor [1].

Because of the extensive bleeding complications experienced by surgeons operating on CPA masses, Harvey Cushing had referred to the anatomic region as "the bloody angle" [2].

Several factors had made early attempts at CPA tumor resection very complicated; a lack of diagnostic capabilities or refined surgical instruments coupled with unreliable anesthesia, limited choices for hemostasis, and an incomplete appreciation of the CPA anatomy. As such, early surgeries had extremely high mortality rates nearing $70 \%$ to $85 \%$. Harvey Cushing, found these mortality rates unacceptable which pushed him to significantly advance the field of CPA surgery [2].

Neural preservation is particularly imperative in the contemporary management of CPA lesions [3]. However, the dissection of the facial nerve may lead to postoperative paresis as the result of the surgical trauma and the disruption of blood supply over a large distance. Facial nerve paralysis associated with CPA surgery has been reported to range from $12 \%$ to $41 \%$ [4] [5]. However, in large vestibular schwannoma, it was reported up to 63\% [6]. Loss of facial nerve function can ultimately result in an inability to blink, secrete tears, or speak properly, thus imposing a significant burden on the patient [7]. Such significant outcomes were once considered a probable morbidity. However, with the advent of facial neuromonitoring, the morbidity has been drastically reduced [8].

Intraoperative direct electrical stimulation and evoked facial nerve electromyography (EMG), to monitor facial nerve function have been well documented, leading to its widespread application in modern surgeries [9].

Some authors reported several benefits of EMG. One of them is determining the anatomical location of the facial nerve. Direct, pinpoint visualization of the nerve may be difficult, as the tumor, its capsule, and bone may displace the nerve in various directions [10].

Moreover, EMG helps prevent unplanned manipulation of the facial nerve by emitting a warning alarm whenever muscle stimulation is detected. This can warn the surgeon of impending danger and thus advise cessation of current actions or alter the surgical planning and strategy, to avoid causing damage to the nerve [11].

Additionally, EMG can help predict the residual function of the nerve postoperatively. When comparing postoperative and baseline stimulation thresholds, patients who require high or higher postoperative currents may have endured some degree of nerve injury [12].

\section{Materials and Methods}

This study was conducted on 30 cases (2 groups, each had 15 patients) with CPA 
lesions that had undergone surgical excision of these lesions performed by retrosigmoid approach (Group A: the patients were operated under continuous IOFNM and Group B: the patients were operated without IOFNM). They were operated upon in neurosurgery departments at Al-Azhar university hospitals between August 2019 and August 2021.

Inclusion criteria: All cases who were admitted for surgical excision of CPA tumours were included. The patients were divided into two groups with comparable size of the tumour, age and operating surgeon. The choice of monitoring or not monitoring, was in a regular order one case was monitored and the next was not monitored.

Exclusion Criteria: Patients with preoperative complete paralysis of facial nerve.

Preoperative assessment: Every patient was subjected to careful history taking, comprehensive general and neurological examination.

Investigations: Every patient was subjected to routine preoperative laboratory investigations in addition to; Audiometry. PTA were indicated in patients presented with symptoms suggestive of vestibulocochlear nerve dysfunction. Imaging. 1) CT brain: CT was done for delineating of the bony anatomy and to show the early expansion of the internal auditory meatus. 2) MRI: Brain MRI with and without contrast was essentially obtained for all cases preoperatively.

Surgical approach: all patients were operated through retrosigmoid approach.

Intraoperative monitoring: IOFNM was done by EMG. Sterile needle electrodes were placed in the ipsilateral orbicularis oculi and orbicularis oris. Electrodes were be placed in contralateral mimetic facial muscles as a control for nonspecific EMG activity (e.g., light anesthesia). Muscle relaxants were avoided during the operation to facilitate the monitoring of EMG activity. Direct electrical stimulation was used as well to localize the nerve.

Patients follow up: All patients were reviewed and followed up at regular interval with special consideration for; Facial nerve functional outcome: It was assessed, and documented immediately postop, after full recovery of the patients, and at 6-month follow up. Facial nerve function was evaluated using $\mathrm{HB}$ grades and was categorized as: A) Excellent (HB grade 1/2). B) Intermediate (HB grade 3/4). C) Poor (HB grade 5/6). The results of the histopathological examination of the specimen taken intraoperatively were documented. MRI brain with contrast was done 3 months postoperatively to determine the extent of the resection of the lesion and detect any possible delayed postop complications.

\section{Results}

We can summarize the statistical comparison and clinical outcome between our two study groups in the following: Regarding demographic data, side and type of lesion, preop facial nerve function, tumour size, extension and postoperative complications, the results revealed that no statistically significant difference could be detected between both studied groups (Table 1, Table 2). 
Table 1. Comparison of side and type of lesions distribution between the two groups.

\begin{tabular}{ccccccc}
\hline & & \multicolumn{2}{c}{ Group A } & \multicolumn{2}{c}{ Group B } & \multirow{2}{*}{ P value } \\
\cline { 3 - 6 } & & Count & $\%$ & Count & $\%$ & \\
\hline \multirow{2}{*}{ Side of lesion } & Left & 7 & $46.7 \%$ & 6 & $40.0 \%$ & \multirow{2}{*}{ Right } \\
\cline { 3 - 6 } Type of lesion & 8 & $53.3 \%$ & 9 & $60.0 \%$ & 0.713 \\
& Meningioma & 2 & $13.3 \%$ & 2 & $13.3 \%$ & \\
& Epidermoid & 1 & $6.7 \%$ & 0 & $0.0 \%$ & 0.718 \\
& Schwannoma & 12 & $80.0 \%$ & 13 & $86.7 \%$ & \\
\hline
\end{tabular}

Table 2. Comparison of postoperative complications between the two group.

\begin{tabular}{lcccccc}
\hline & & \multicolumn{2}{c}{ group A } & \multicolumn{2}{c}{ group B } & \multirow{2}{*}{ P value } \\
\cline { 3 - 6 } & & Count & $\%$ & Count & $\%$ & \\
\hline & Wound infection & 0 & $0.0 \%$ & 1 & $6.7 \%$ & \\
\cline { 3 - 6 } Postoperative & Pneumocephalus & 1 & $6.7 \%$ & 1 & $6.7 \%$ & \\
complications & Hydrocephalus & 1 & $6.7 \%$ & 0 & $0.0 \%$ & 1 \\
& CSF leak & 1 & $6.7 \%$ & 0 & $0.0 \%$ & \\
& None & 12 & $80.0 \%$ & 13 & $86.7 \%$ & \\
\hline
\end{tabular}

The two groups have comparable age of patients, preop facial nerve function, sizes of the tumour and operating surgeon (Tables 3-5, Figure 1, Figure 2).

Table 3. Age and Sex distribution comparison between the two groups.

\begin{tabular}{|c|c|c|c|c|c|c|}
\hline & & \multicolumn{2}{|c|}{ Group A } & \multicolumn{2}{|c|}{ Group B } & \multirow{2}{*}{$P$ value } \\
\hline & & Count & $\%$ & Count & $\%$ & \\
\hline \multirow{6}{*}{ Age group } & $2^{\text {nd }}$ decade & 1 & $6.7 \%$ & 0 & $0.0 \%$ & \multirow{6}{*}{0.970} \\
\hline & $3^{\text {rd }}$ decade & 2 & $13.3 \%$ & 1 & $6.7 \%$ & \\
\hline & $4^{\text {th }}$ decade & 5 & $33.3 \%$ & 7 & $46.7 \%$ & \\
\hline & $5^{\text {th }}$ decade & 4 & $26.7 \%$ & 4 & $26.7 \%$ & \\
\hline & $6^{\text {th }}$ decade & 2 & $13.3 \%$ & 2 & $13.3 \%$ & \\
\hline & $7^{\text {th }}$ decade & 1 & $6.7 \%$ & 1 & $6.7 \%$ & \\
\hline \multirow{2}{*}{ Sex } & Female & 9 & $60.0 \%$ & 10 & $66.7 \%$ & \multirow{2}{*}{0.705} \\
\hline & Male & 6 & $40.0 \%$ & 5 & $33.3 \%$ & \\
\hline
\end{tabular}

Table 4. Shows comparison between preop facial nerve function between the two groups.

\begin{tabular}{|c|c|c|c|c|c|c|}
\hline & & \multicolumn{2}{|c|}{ group A } & \multicolumn{2}{|c|}{ group B } & \multirow{2}{*}{$P$ value } \\
\hline & & Count & $\%$ & Count & $\%$ & \\
\hline \multirow{5}{*}{$\begin{array}{c}\text { Preoperative } \\
\text { House-Brackmann } \\
\text { grade }\end{array}$} & Grade I & 11 & $73.3 \%$ & 11 & $73.3 \%$ & \multirow{5}{*}{0.713} \\
\hline & Grade II & 2 & $13.3 \%$ & 2 & $13.3 \%$ & \\
\hline & Grade III & 1 & $6.7 \%$ & 0 & $0.0 \%$ & \\
\hline & Grade IV & 1 & $6.7 \%$ & 1 & $6.7 \%$ & \\
\hline & Grade V & 0 & $0.0 \%$ & 1 & $6.7 \%$ & \\
\hline
\end{tabular}


Table 5. Comparisons between preop radiological size and extension.

\begin{tabular}{|c|c|c|c|c|c|c|}
\hline & & \multicolumn{2}{|c|}{ group A } & \multicolumn{2}{|c|}{ group B } & \multirow{2}{*}{$P$ value } \\
\hline & & Count & $\%$ & Count & $\%$ & \\
\hline \multirow{5}{*}{$\begin{array}{l}\text { Preop Hannover } \\
\text { Classification } \\
\text { of Tumor Extension }\end{array}$} & $\mathrm{T} 2$ & 1 & $6.7 \%$ & 0 & $0.0 \%$ & \multirow{5}{*}{1} \\
\hline & T3a & 1 & $6.7 \%$ & 1 & $6.7 \%$ & \\
\hline & $\mathrm{T} 3 \mathrm{~b}$ & 2 & $13.3 \%$ & 2 & $13.3 \%$ & \\
\hline & $\mathrm{T} 4 \mathrm{a}$ & 9 & $60.0 \%$ & 10 & $66.7 \%$ & \\
\hline & $\mathrm{T} 4 \mathrm{~b}$ & 2 & $13.3 \%$ & 2 & $13.3 \%$ & \\
\hline \multirow{4}{*}{$\begin{array}{l}\text { Size of the lesion } \\
(\mathrm{mm}) \text { in MRI }\end{array}$} & $<30$ & 1 & $6.7 \%$ & 0 & $0.0 \%$ & \multirow{4}{*}{1} \\
\hline & $>30$ & 8 & $53.3 \%$ & 9 & $60.0 \%$ & \\
\hline & $>40$ & 4 & $26.7 \%$ & 5 & $33.3 \%$ & \\
\hline & $>50$ & 2 & $13.3 \%$ & 1 & $6.7 \%$ & \\
\hline
\end{tabular}

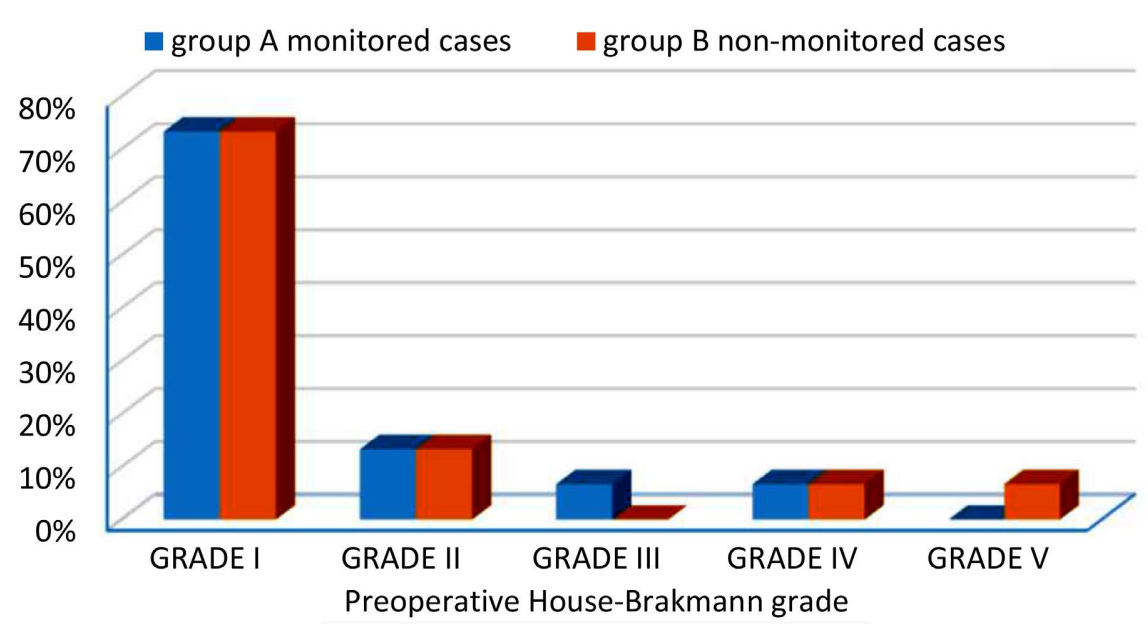

Figure 1. Comparison between preop facial nerve function between the two groups.

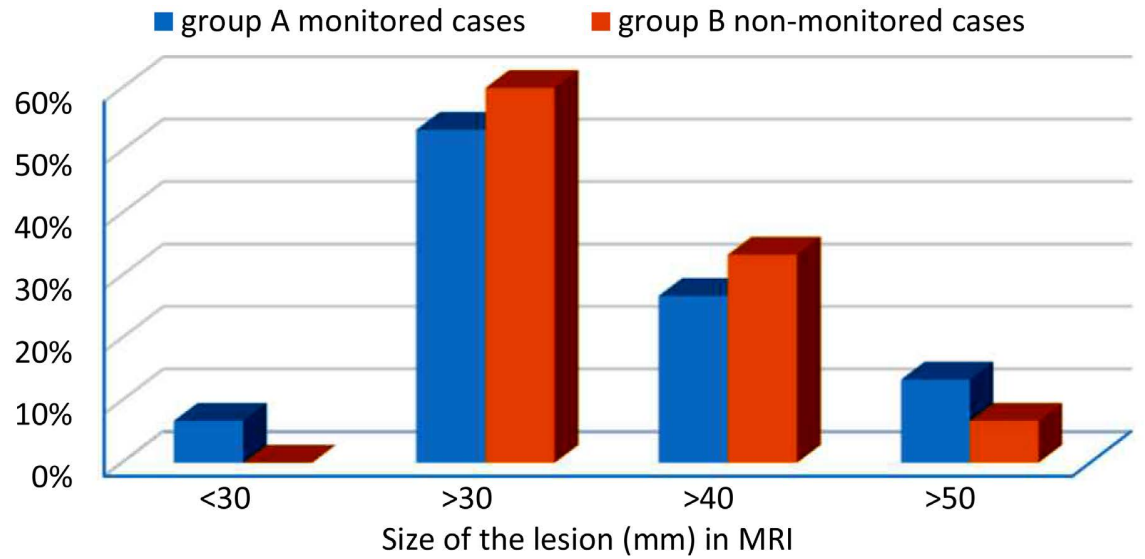

Figure 2. Comparison of preop. tumour size between the two groups.

No statistically significant difference could be detected between both studied groups as regard anatomical facial nerve preservation, which may be due to small patient sample. However, we can notice that the only case with disrupted facial 
nerve was in group B. The tumour size in this case was $>50 \mathrm{~mm}$.

Excellent facial nerve function (HB Grade I and II) was higher in group A than group B, immediately and at 6-month post op (80\% and $93 \%$ VS $53.3 \%$ and 66.7\%) (Table 6, Table 7, Figure 3, Figure 4). However, no statistically significant $\mathrm{P}-\mathrm{V}$ alue between both groups.

Table 6. Comparison of facial nerve function immediately postoperatively between the two groups.

\begin{tabular}{ccccccc}
\hline & & \multicolumn{2}{c}{ Group A } & \multicolumn{2}{c}{ Group B } & \multirow{2}{*}{ P value } \\
\cline { 3 - 6 } & & Count & $\%$ & Count & $\%$ & \\
\hline & Grade I & 11 & $73.3 \%$ & 7 & $46.7 \%$ & 0.136 \\
& Grade II & 1 & $6.7 \%$ & 1 & $6.7 \%$ & 1 \\
$\begin{array}{c}\text { Facial nerve function } \\
\text { immediately postoperatively } \\
\text { using HB scale }\end{array}$ & Grade III & 2 & $13.3 \%$ & 1 & $6.7 \%$ & 1 \\
& Grade IV & 1 & $6.7 \%$ & 3 & $20 \%$ & 0.598 \\
& Grade V & 0 & $0.0 \%$ & 2 & $13.3 \%$ & 0.483 \\
& Grade VI & 0 & $0.0 \%$ & 1 & $6.7 \%$ & 1 \\
\hline
\end{tabular}

Table 7. Shows Comparison of Facial nerve function six-month postoperatively.

\begin{tabular}{ccccccc}
\hline & & \multicolumn{2}{c}{ Group A } & \multicolumn{2}{c}{ Group B } & \multirow{2}{*}{ P value } \\
\cline { 3 - 6 } & & Count & $\%$ & Count & $\%$ & \\
\hline & Grade I & 12 & $80 \%$ & 8 & $53.3 \%$ & 0.121 \\
& Grade II & 2 & $13.3 \%$ & 2 & $13.3 \%$ & 1 \\
$\begin{array}{c}\text { Facial nerve function } \\
\text { 6-month }\end{array}$ & Grade III & 1 & $6.7 \%$ & 1 & $6.7 \%$ & 1 \\
$\begin{array}{c}\text { postoperatively } \\
\text { Grade IV }\end{array}$ & 0 & $0.0 \%$ & 2 & $13.3 \%$ & 0.483 \\
& Grade V & 0 & $0.0 \%$ & 1 & $6.7 \%$ & 1 \\
& Grade VI & 0 & $0.0 \%$ & 1 & $6.7 \%$ & 1 \\
\hline
\end{tabular}

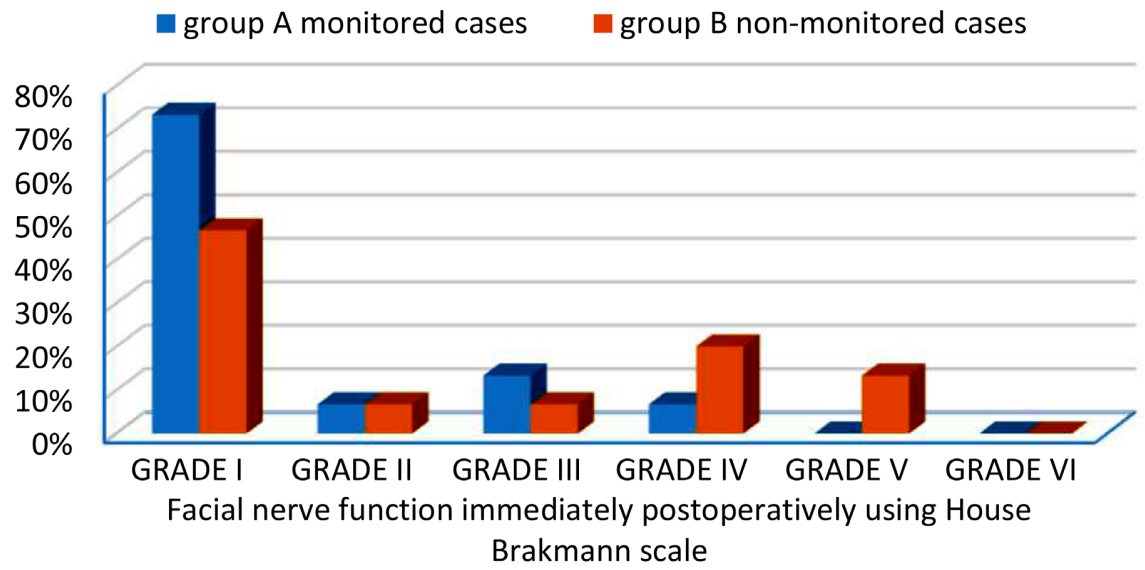

Figure 3. Comparison of facial nerve function immediately postoperatively between the two groups. 


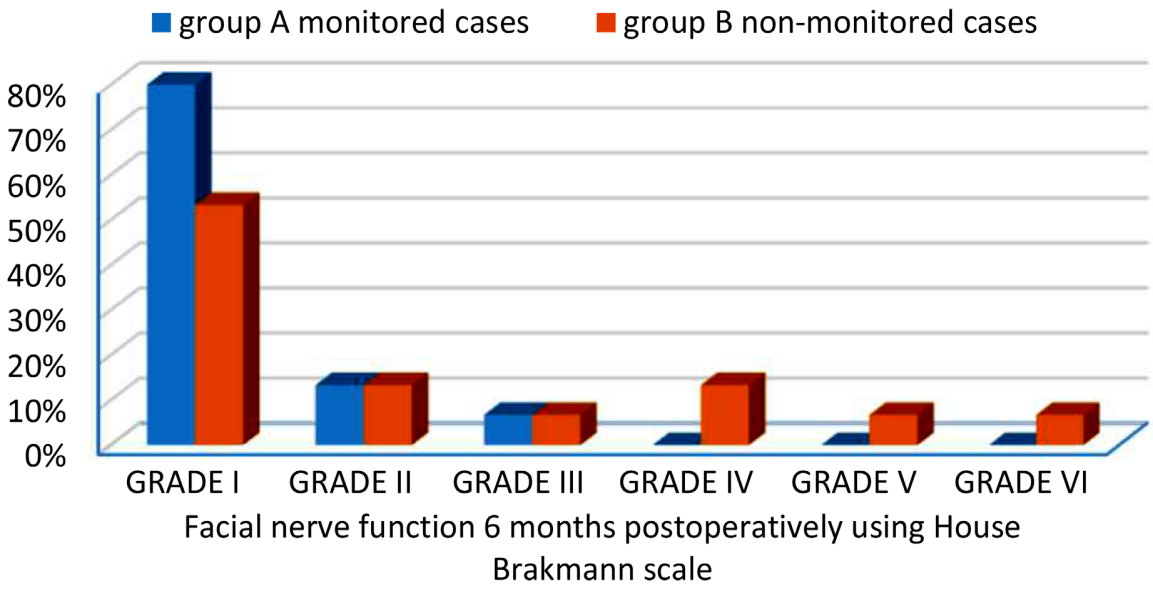

Figure 4. Comparison of facial nerve function six-month postoperatively.

Intermediate (HB Grade III and VI) and Poor (HB Grade V and VI) facial nerve function was higher in group B than group A immediately and 6-month postop (46.7\% and $33.3 \%$ VS $20 \%$ and $6.6 \%$ ). These results reflect the better facial nerve function outcome with IOFNM. Even though, no statistically significant difference could be detected between both studied groups which may be due to small patient sample (Table 8).

Table 8. Comparison of facial nerve function immediately and six-month postoperatively categorized as excellent, intermediate and poor.

\begin{tabular}{ccccccc}
\hline & & \multicolumn{2}{c}{ Group A } & \multicolumn{2}{c}{ Group B } & \multirow{2}{*}{} \\
\cline { 3 - 6 } & & Count & $\%$ & Count & $\%$ & \\
\hline \multirow{2}{*}{$\begin{array}{c}\text { Facial nerve function } \\
\text { immediately postop. }\end{array}$} & Excellent & 12 & $80 \%$ & 8 & $53.3 \%$ & \\
& Intermediate & 3 & $20 \%$ & 4 & $26.7 \%$ & 0.208 \\
& Poor & 0 & $0.00 \%$ & 3 & $20 \%$ & \\
\hline \multirow{2}{*}{ Function 6-month postop. } & Intermediate & 1 & $6.7 \%$ & 3 & $20 \%$ & 0.201 \\
& Poor & 0 & $0.00 \%$ & 2 & $13.3 \%$ & \\
\hline
\end{tabular}

Regarding the extent of tumor resection; no statistically significant difference could be detected between both studied groups. Nevertheless, observations provide evidence that the percentage of lesions that have undergone GTR was higher in group B (86.7\%) compared to group A (66.7\%). Furthermore, the percentage of lesions that was subtotally excised was higher in group A. This may reflect a negative impact of monitoring on the decision of surgeon to perform GTR. A large patient sample is required to validate this observation (Table 9, Figure 5).

Our results revealed that in tumors with Hannover class T1, T2, T3a and T3b, the rate of anatomical facial nerve preservation was $100 \%$. The only one patient (3.3\%) in which anatomical preservation could not be possible had Hannover tumor extension T4b and it was of large sized tumor $(>50 \mathrm{~mm})$, adherent and 
Table 9. Comparison of extent of tumor resection between the two groups.

\begin{tabular}{ccccccc}
\hline & & \multicolumn{2}{c}{ Group A } & \multicolumn{2}{c}{ Group B } & \multirow{2}{*}{ P value } \\
\cline { 3 - 6 } & & Count & $\%$ & Count & $\%$ & \\
\hline \multirow{3}{*}{$\begin{array}{c}\text { Extent of tumor } \\
\text { resection }\end{array}$} & STR & 3 & $20.00 \%$ & 1 & $6.70 \%$ & \\
& NTR & 2 & $13.30 \%$ & 1 & $6.70 \%$ & 0.477 \\
& GTR & 10 & $66.70 \%$ & 13 & $86.70 \%$ & \\
\hline
\end{tabular}

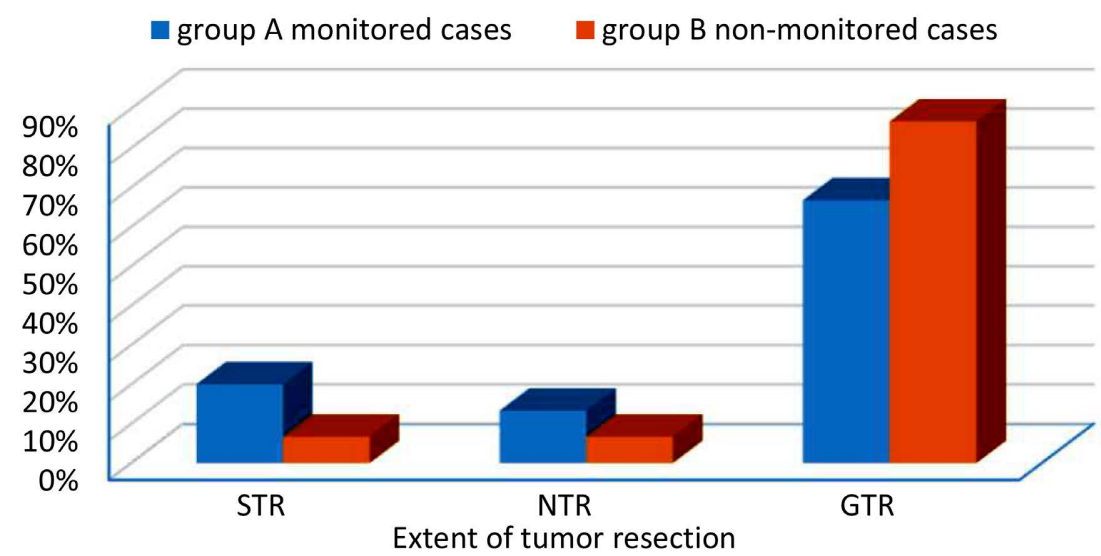

Figure 5. Comparison of Extent of tumor resection between the two groups.

compressing the surrounding structures.

There was an inverse relationship between tumour size and the extent of surgical tumor resection as there was statistically significant correlation (P-value 0.001) (Table 10, Figure 6).

Table 10. Relationship between size of lesion in $\mathrm{mm}$ and the extent of tumor resection.

\begin{tabular}{|c|c|c|c|c|c|c|c|c|c|c|}
\hline & & \multicolumn{8}{|c|}{ Size of the lesion (mm) in MRI } & \multirow{3}{*}{$\begin{array}{c}\text { P } \\
\text { value }\end{array}$} \\
\hline & & \multicolumn{2}{|c|}{$<30$} & \multicolumn{2}{|c|}{$>30$} & \multicolumn{2}{|c|}{$>40$} & \multicolumn{2}{|c|}{$>50$} & \\
\hline & & Count & $\%$ & Count & $\%$ & Count & $\%$ & Count & $\%$ & \\
\hline \multirow{3}{*}{$\begin{array}{l}\text { Extent of } \\
\text { tumor } \\
\text { resection }\end{array}$} & STR & 0 & $0.0 \%$ & 0 & $0.0 \%$ & 2 & $22.2 \%$ & 2 & $66.7 \%$ & \multirow{3}{*}{0.001} \\
\hline & NTR & 0 & $0.0 \%$ & 0 & $0.0 \%$ & 3 & $33.3 \%$ & 0 & $0.0 \%$ & \\
\hline & GTR & 1 & $100.0 \%$ & 17 & $100.0 \%$ & 4 & $44.4 \%$ & 1 & $33.3 \%$ & \\
\hline
\end{tabular}

Size of the lesion ( $\mathrm{mm}$ ) in MRI

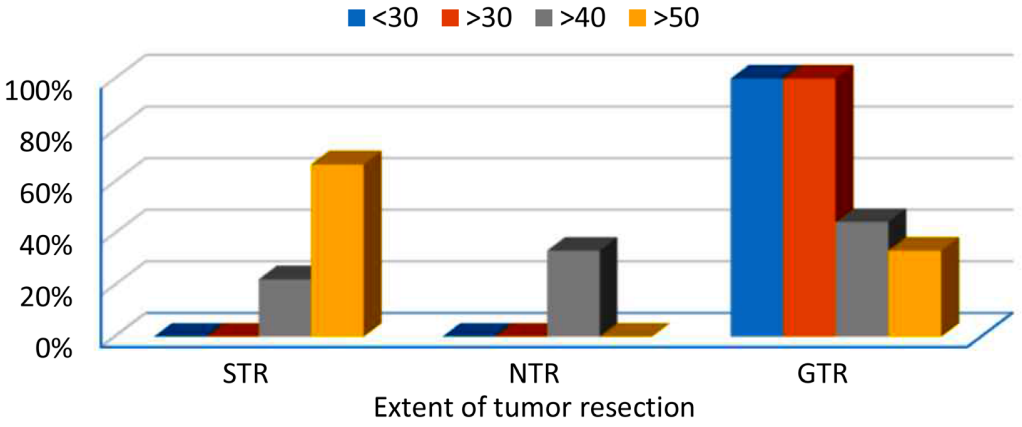

Figure 6. Relationship between size of lesion in $\mathrm{mm}$ and the extent of tumor resection. 
There was statistically significant correlation between the size of lesion and postop facial nerve function ( $\mathrm{p}$-value 0.014 ); The larger the size of the lesion, the less the percentage of postop excellent to intermediate facial nerve function (Table 11, Figure 7, Figure 8).

Table 11. The relationship between size of the tumor and postoperative facial nerve function preservation.

\begin{tabular}{|c|c|c|c|c|c|c|c|c|c|c|}
\hline & & \multicolumn{8}{|c|}{ Size of the lesion $(\mathrm{mm})$ in MRI } & \multirow{3}{*}{$P$ value } \\
\hline & & \multicolumn{2}{|c|}{$<30$} & \multicolumn{2}{|c|}{$>30$} & \multicolumn{2}{|c|}{$>40$} & \multicolumn{2}{|c|}{$>50$} & \\
\hline & & Count & $\%$ & Count & $\%$ & Count & $\%$ & Count & $\%$ & \\
\hline \multirow{2}{*}{$\begin{array}{l}\text { Facial nerve function } \\
\text { immediately postop }\end{array}$} & Excellent to intermediate & 1 & $100.0 \%$ & 17 & $100.0 \%$ & 8 & $88.9 \%$ & 1 & $33.3 \%$ & \multirow{2}{*}{0.014} \\
\hline & Poor function & 0 & $0.0 \%$ & 0 & $0.0 \%$ & 1 & $11.1 \%$ & 2 & $66.7 \%$ & \\
\hline \multirow{2}{*}{$\begin{array}{l}\text { Facial nerve function } \\
6 \text { months postop }\end{array}$} & Excellent to intermediate & 1 & $100.0 \%$ & 17 & $100.0 \%$ & 9 & $100.0 \%$ & 1 & $33.3 \%$ & \multirow{2}{*}{0.014} \\
\hline & Poor function & 0 & $0.0 \%$ & 0 & $0.0 \%$ & 0 & $0.0 \%$ & 2 & $66.7 \%$ & \\
\hline
\end{tabular}

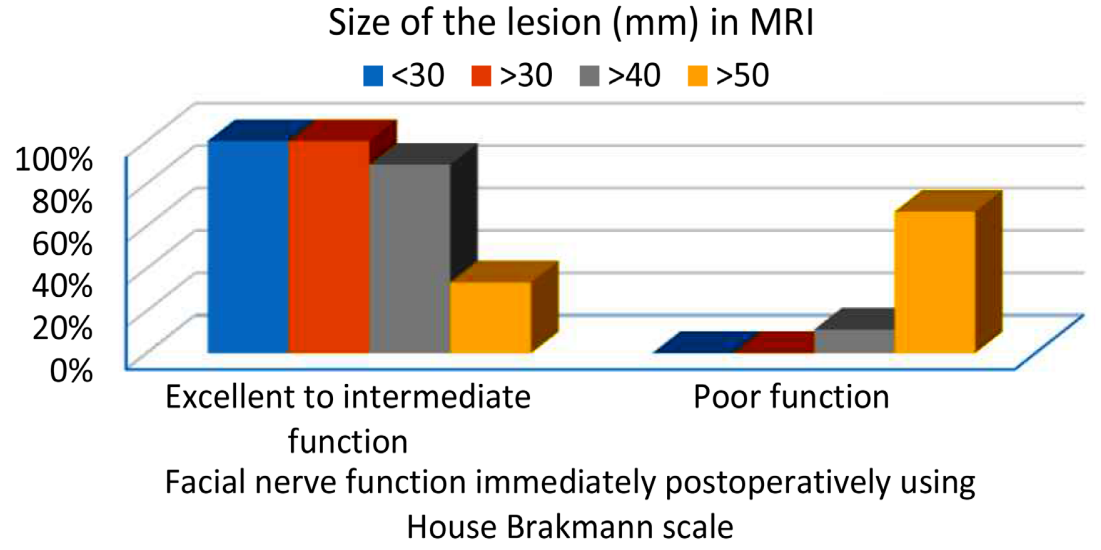

Figure 7. The relationship between size of the tumor and immediately postoperative facial nerve function preservation.

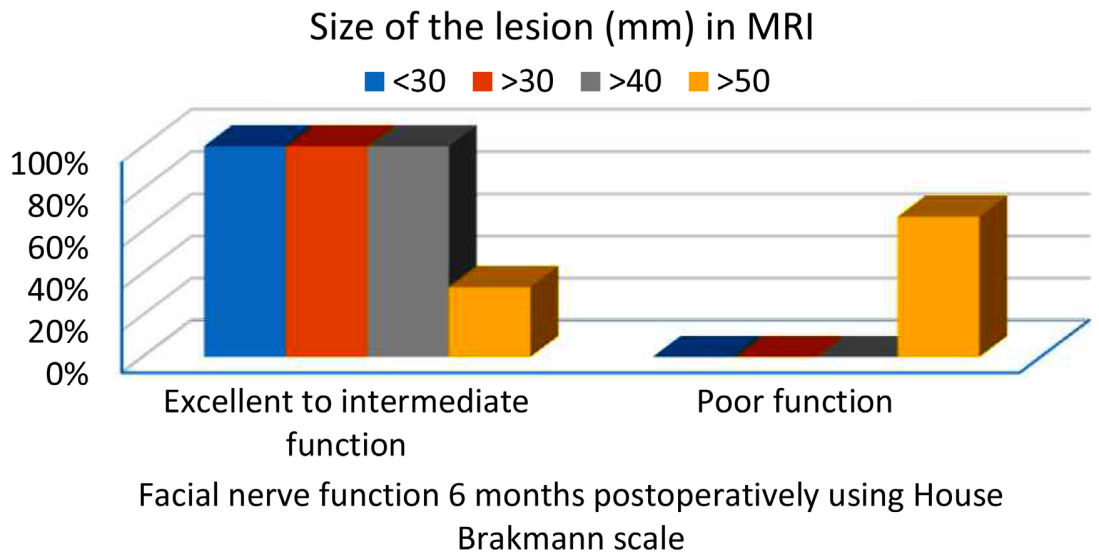

Figure 8. The relationship between size of the tumor and six-month postoperative facial nerve function preservation.

\section{Illustrative Cases}

Case (1): 50 yrs old female, presented with gradual progressive hearing loss of 
the left ear for three years associated with tinnitus. Examination revealed left sided SNHL, and there was no facial palsy. MRI showed large partially defined mass lesion with large dural based which is centered in the left CPA cistern. It has irregular serrated medial border that contacts the left cerebellum hemisphere. The mass demonstrated iso signal intensity and avid enhancement on post gadolinium images. The patient was operated with microscopic excision of the right CPA mass through the left retrosigmoid approach under IOFNM. Post op, patient has left sided facial palsy grade III which was improved to grade II at 6-month follow up period. Histopathology showed CPA meningioma grade II. Patient was referred to SRS for the residual tumour (Figures 9-11).

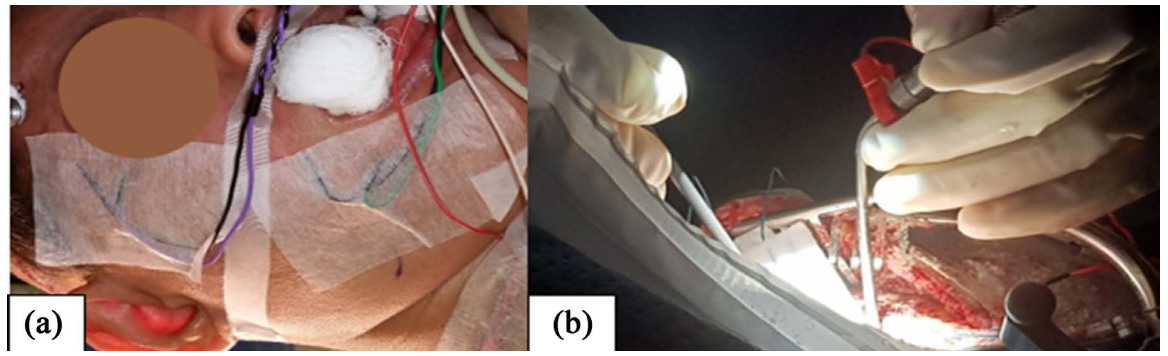

Figure 9. (a) Sites of recording electrodes, (b) Suction probe used as monopolar stimulator.
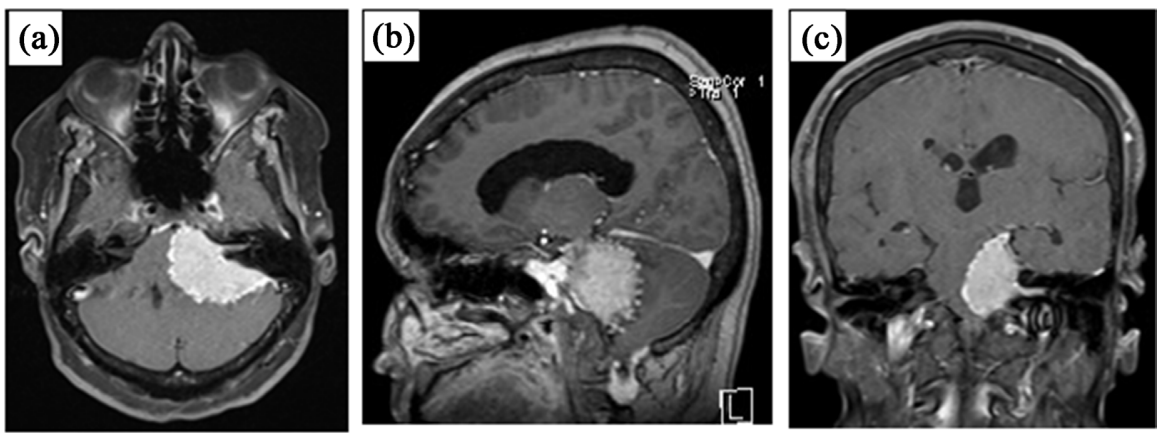

Figure 10. Preoperative MRI Brain T1 post contrast (a) Axial, (b) Sagittal and (c) Coronal imaging; showing left CPA mass lesion.
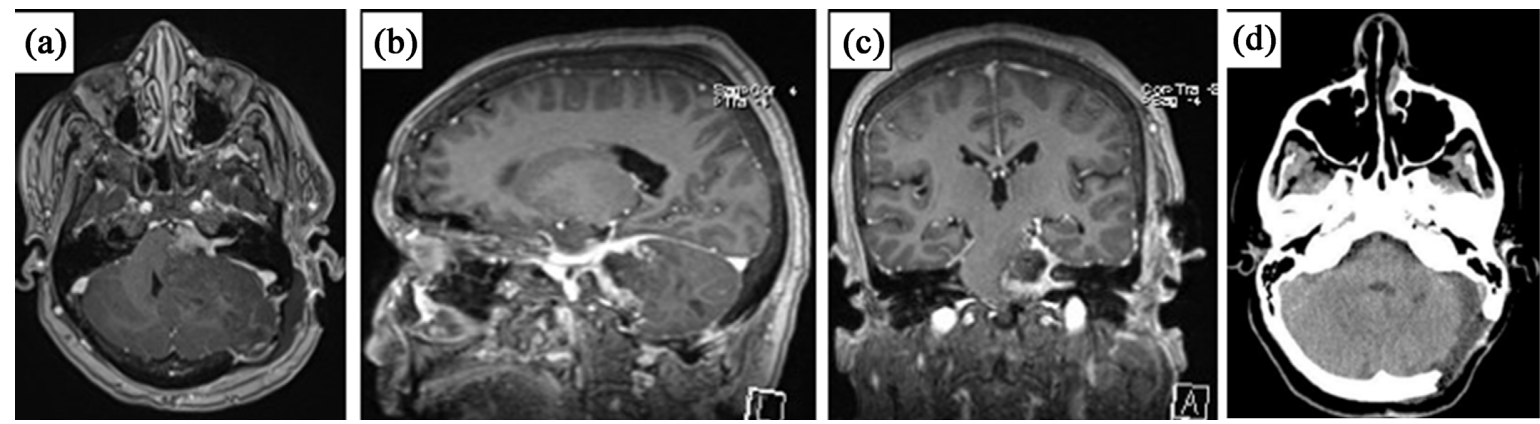

Figure 11. Postoperative MRI Brain T1 post contrast (a) Axial, (b) Sagittal and (c) Coronal images; showing residual tumour. And (d) Postop CT brain showing the craniotomy site.

Case (2): 41 yrs old female, presented with left sided non-pulsatile tinnitus and progressive hearing loss of the left ear for 2 years. Examination revealed left 
sided SNHL, and there was no facial palsy. MRI showed large well defined mass lesion which is centered in the left IAC. The patient was operated with microscopic excision of the left CPA mass through the left retrosigmoid Approach without IOFNM. Post op, patient has left sided facial palsy grade IV which was improved to grade III at 6-month follow up. Histopathology showed VS (Figures 12-14).
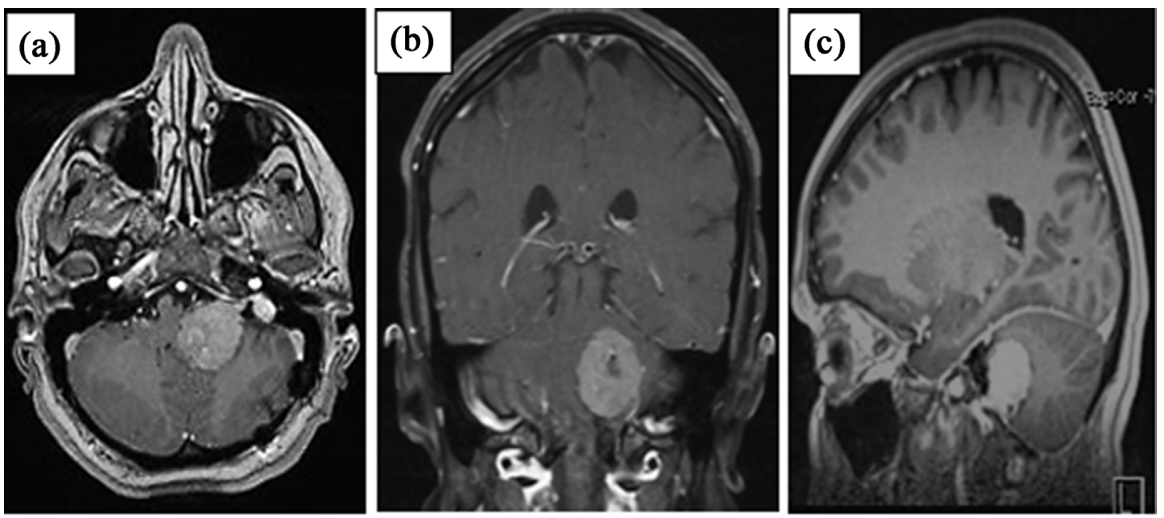

Figure 12. Preoperative MRI Brain T1 post contrast (a) Axial, (b) Coronal and (c) Sagittal imaging; showing left CPA mass.

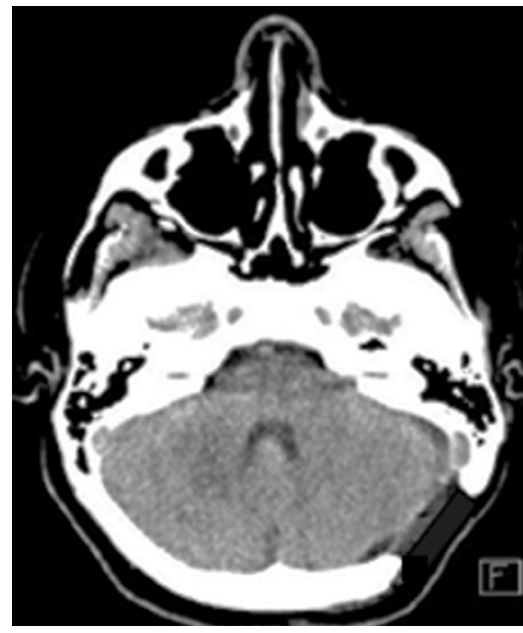

Figure 13. Postoperative CT brain.
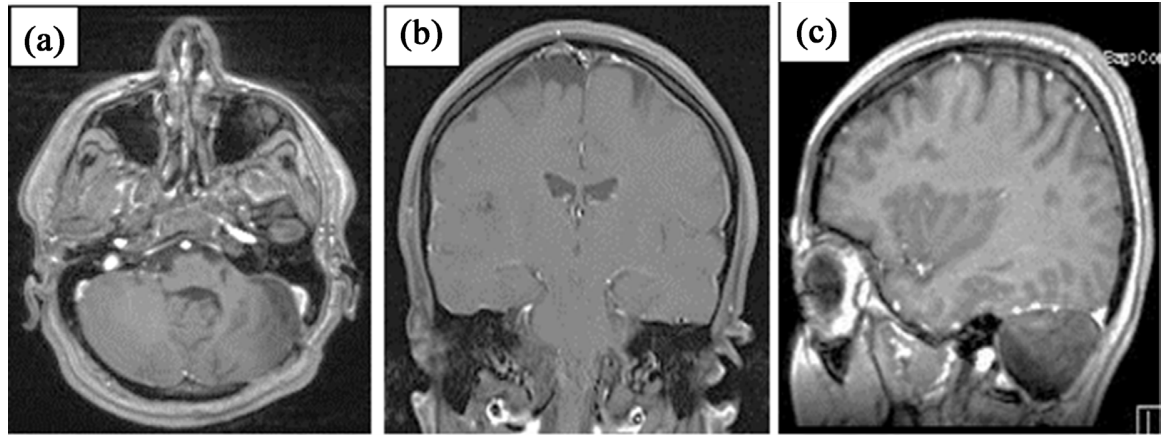

Figure 14. Postoperative MRI Brain T1 post contrast axial (a) Axial, (b) Coronal and (c) Sagittal imaging; Showing almost total excision. 


\section{Discussion}

The goal of CPA surgery should be total tumor removal with preservation of cranial nerve functions. In experienced hands complete tumor removal is achieved in $80 \%$ to $99 \%$ of cases [3]. However, in certain instances it becomes impossible to achieve complete tumor resection due to the tumor's intimate relationship with important structures, such as the facial nerve, brainstem, vessels, and other nerves in the CPA, without compromising such structures [13]. Intraoperative vital signs changes or excessive bleeding may also force the procedure to be abandoned before total tumor excision has been achieved [14].

The main purpose of intraoperative monitoring is to make the surgical team aware of the ongoing changes in the neural function, thereby permitting modifications in surgical strategies that can ultimately avoid neural damage [15]. Achieving this purpose demands the use of various monitoring techniques that are now available. Standard FN monitoring techniques during CPA surgery include direct electrical stimulation (DES) and free-running EMG [16]. Our study included nineteen females (63.3\%) and eleven males (36.7\%). Their ages ranged from 19 years to 62 years with a mean age of 41.93 years with (SD) standard deviation 11.14. The highest age incidence of our cases was during the fourth and fifth decades of life. It is well recognized that there is no statistically significant difference, as regard of age and sex of patients, on the outcome of cranial nerves preservation at CPA surgeries [17]. According to literatures, most tumors in the CPA cistern are VS (75\%), followed by meningiomas (10\%) and epidermoid tumors (5\%). Uncommon neoplasms that may involve the CPA include metastatic disease, facial nerve schwannoma, exophytic, and hemangioma. Nonneoplastic lesions that may occur include aneurysms arising from the vertebrobasilar arteries, arachnoid cysts, and lipomas [18]. In this present study, according to histopathological reports, VS were the most common lesion $(25 / 30 \rightarrow$ $83.3 \%)$, followed by meningioma $(4 / 30 \rightarrow 13.33 \%)$. Epidermoid was the least common $(1 / 30 \rightarrow 3.3 \%)$.

In our study, most of cases (56.7\%) had tumour size of $30-40 \mathrm{~mm}$ followed by tumour size 40 - $50 \mathrm{~mm}$ (30\%). Based on Preop Hannover classification of tumor extension, 19 patients (63.3\%) were T4a, followed by T3b (13.3\%) and T4b (13.3\%). In the study of Matthies and samii, 470 out of 1000 cases of VSs were small size tumors $(<30 \mathrm{~mm})$ [19]. Falcioni et al., retrospectively reviewed 1151 cases with VSs, the median tumor size was $1.6 \mathrm{~cm}$ [20]. This difference, regarding preop lesion size and extension, between our study and all previous studies, is due to the fact that most our patients with small size lesion $<3 \mathrm{~cm}$ preferred SRS as an alternative option to surgery.

Koos, stated that anatomical preservation of the facial nerve is the rule today and is achieved in $93 \%$ to $99 \%$ of cases in his study [21]. Samii et al., reported that the anatomical preservation of the facial nerve greatly depends upon the tumor extension and Hannover tumor extension scale was used in his series. He found anatomical preservation of the facial nerve was possible in 197/200 pa- 
tients $(98.5 \%)$. In tumors with classes $\mathrm{T} 1, \mathrm{~T} 2$, and $\mathrm{T} 3$ extension, the rate of facial nerve preservation was $100 \%$. In $1.5 \%$ of patients, the integrity of the nerve could not be preserved; all of these patients suffered large VSs, corresponding to class T4 extension. In the study of Rinaldi et al., which included 97 consecutive patients undergoing surgical excision of sporadic unilateral VS, anatomic preservation of the facial nerve was achieved in $97 \%$ of patients. The incidence of postoperative facial palsy was found to be statistically correlated to tumor size, but not to the surgical approach used and to extent of tumor penetration in the IAC. Complete tumor excision was achieved in $94 \%$ of cases [22]. In our present study, anatomical facial nerve preservation was done in 29 patients (96.66\%), In one patient (3.33\%) facial nerve integrity could not be preserved. In tumors with Hannover class T1, T2 and T3, the rate of anatomical fascial nerve preservation was $100 \%$ but, the only one patient in which anatomical preservation could not be possible had Hannover tumor extension $\mathrm{T} 4 \mathrm{~b}$ and it was of large sized tumor (>50 mm), adherent and compressing to the surrounding structures. This patient was not operated under IOFNM.

The risk of facial nerve palsy after microsurgical removal of CPA lesions cannot be entirely eliminated, even with refinements in surgical techniques [23]. Several factors including tumor size and extension, tumor consistency, a surgeon's operative experience and usage of intraoperative neurophysiological monitoring have an important impact on prediction of post op facial nerve preservation [24]. Other authors found that tumor size is the most important predictor of facial nerve outcome, and that age, extent of resection and surgical approach do not independently predict facial palsy [25]. This may be explained by the greater tension of facial nerve due to the tumor growth in patients with large VS. cases. Samii et al., retrospective study showed that complete tumor removal was achieved in $98 \%$ of patients. It is worth mentioning that $34 \%$ of the patients had tumour extension $\leq \mathrm{T} 3 \mathrm{a}$. By the last follow-up examination, excellent or good facial nerve function had been achieved in $81 \%$ of the cases [3]. In the study of Breun et al., which included 483 patients with VS; useful facial function (HB grades I-III) was preserved in $80 \%$ of cases (392/489): for small tumors it was $86 \%$ and for large tumors it was $77 \%$. A total of 108 patients had a severe dysfunction according to $\mathrm{HB}$ grades IV-VI. The functional preservation rates correlated significantly $(\mathrm{P}<0.05)$ with tumor extension and size. All cases were operated under IOFNM [26]. In our present study, immediate postoperative function grade I, II were achieved in $66.7 \%$, and at six months postoperatively, it was achieved in $80 \%$. There was statistically significant correlation between the size of lesion and postop facial nerve function (p-value 0.014). Excellent to intermediate facial nerve function in tumour size $<40 \mathrm{~mm}$ was $100 \%$, while in tumour $>$ $50 \mathrm{~mm}$ decreased to $33.3 \%$.

Regarding the extent of surgical radicality, GTR was achieved in $76.7 \%(23 / 30)$ which is lower than that achieved by Sami $M$ et al., However, in the study of Breun et al., GTR was performed in 349 cases (69.5\%), and NTR with tissue 
capsule was performed in the remaining 135 cases (26.9\%). Partial resection was carried out in 18 cases (3.6\%). According to Jung et al., the extension and size of the CPA tumor is the main predictor of the extent of tumor resection [27]. In our study, there was an inverse relationship between the extent of surgical tumor resection and tumour size as there is statistically significant P-Value $0.001(<0.05)$. This means when tumour size increase, the chance of GTR decrease. The percentage of GTR was $100 \%(18 / 18)$ in lesion < $40 \mathrm{~mm}$, but it decreased to $41.7 \%$ $(5 / 12)$ in tumour size $>40 \mathrm{~mm}$. We observed that significant difference between the percentage of patients with excellent to intermediate function (100\%) and poor function $(0 \%)$ in the patient who have undergone NTR compared to those with GTR ( $95.7 \%$ and $4.3 \%$ respectively). There may be a correlation between extent of tumor resection and postop facial nerve function preservation; Even though, we couldn't prove this observation statistically. A large patient sample may figure out this observation.

In fact, a review of the most recently published large studies of surgical resection of VS shows a persistent focus on GTR as the main goal of treatment [3] [20]. Even in these contemporary expert microsurgical series that focus on GTR, rates of facial dysfunction remain high; good postoperative facial nerve function (HB grades I and II) range from 33\% to $75 \%$ for patients with large tumors. At the same time, radiosurgery advanced as a treatment for VS [28]. Anaizi et al., investigated the outcome of facial nerve preservation surgery, in 52 patients with large VS, which was performed by limiting dissection of the interface between the tumor and the cisternal portion of the facial nerve. If a small piece of capsule was found densely adherent to the facial nerve or the brainstem, it was left behind. At the end of this study, Anaizi et al., supported the effectiveness and safety of a staged strategy to maximize preservation, monitor residual tumor, and follow with radiation therapy when needed. This strategy differs from other recent large studies that continue to advocate GTR as the main treatment [3]. By searching for large case series, we could find that Schwartz et al., had conducted retrospective and prospective study including 400 patients with a VS of $\geq 2.5 \mathrm{~cm}$ undergoing translab microsurgical resection. At the end of their study, they concluded that NTR and STR are associated with significantly better facial nerve outcomes than GTR with an acceptable rate of tumor regrowth and need for retreatment [29]. Chen et al., evaluated the behavior of residual tumors and facial nerve outcomes after incomplete excision of VSs in 111 patients. In the 105 patients with normal preoperative facial nerve function, postoperative facial nerve function was HB Grades I and II in 51 patients (48.57\%), HB Grade III in 34 patients (32.38\%), and HB Grades IV - VI in 20 patients (19.05\%). Seven patients (6.3\%) showed evidence of tumor regrowth on follow-up MRI. All 7 patients (100\%) who showed evidence of tumor regrowth had undergone STR. No patient in the NTR group exhibited regrowth. The follow-up period ranged from 12 to 156 months (mean 45.4 months). Chen et al., concluded that there is undoubtedly merit for NTR and STR for preservation of the facial nerve. Ferroli et al., described the details of technique for facial nerve sparing surgery for large VS 
which included patient-tailored image-guided craniotomy, continuous intraoperative neurophysiological monitoring, intracapsular wide tumor debulking, and only final extracapsular dissection with FN course identification and brainstem decompression. A small amount of residual tumor $\left(0.5-1 \mathrm{~cm}^{3}\right)$ along the FN is accepted in order to not damage the nerve. Postoperative radiosurgery workup is then recommended to obtain good disease control. FN preservation rate (HB grade 1 - 2) was above 93\% (at 6-month follow-up). They concluded that NTR/ STR resection with FN function sparing is a valid option for large VS [30]. Considering that VSs are benign slowly growing tumors, incomplete removal can be used as a strategy to reduce postoperative morbidity, and therefore it is important to know the behavior of the residual tumor in incomplete resections [30].

Although all recent studies recommended routine use of IOFNM during CPA surgery, there have been no recent formal comparative clinical trials to assess the benefits of surgery with monitoring over surgery without monitoring. Moreover, all old comparative studies (Table 12) are based on retrospective cases and most of them did not comment on degree of tumour resection in both groups.

The strongest argument against using electrical markers as predictors for poor function was based on the observation that patients with electrical silence, or absent responses at the end of surgery, did not necessarily develop a permanent facial paralysis. Whereas several markers can be reliably used to predict good facial function, the ability to predict poor function is still limited. Additionally, the available recommendations concerning IOFNM are all level III. Consequently, further prospective studies with large patient samples are required to solve these debates [31].

\section{Conclusions}

IOFNM can help, but cannot guarantee, the preservation of facial nerve. Furthermore, it is merely a technical adjunct and does not replace surgical skills, knowledge of anatomy and experience.

We agreed with the congress of neurological surgeons' systematic review and evidence-based guidelines on intraoperative cranial nerve monitoring in VS Surgery which includes [31]:

1) Level 3: It is recommended that intraoperative facial nerve monitoring be routinely utilized during VS surgery to improve long-term facial nerve function.

2) Level 3: IOFNM can be used to accurately predict favorable longterm facial nerve function after VSs surgery. However, the absence of favorable testing in the setting of an anatomically intact facial nerve does not reliably predict poor long-term function and therefore cannot be used to direct decision-making regarding the need for early reinnervation procedures.

3) Level 3: Poor intraoperative EMG electrical response of the facial nerve should not be used as a reliable predictor of poor long-term facial nerve function.

\section{Limitations of Our Study}

Our findings would have been strengthened by longer duration of clinical facial 
Table 12. Summary of the reported comparative studies in facial nerve monitoring.

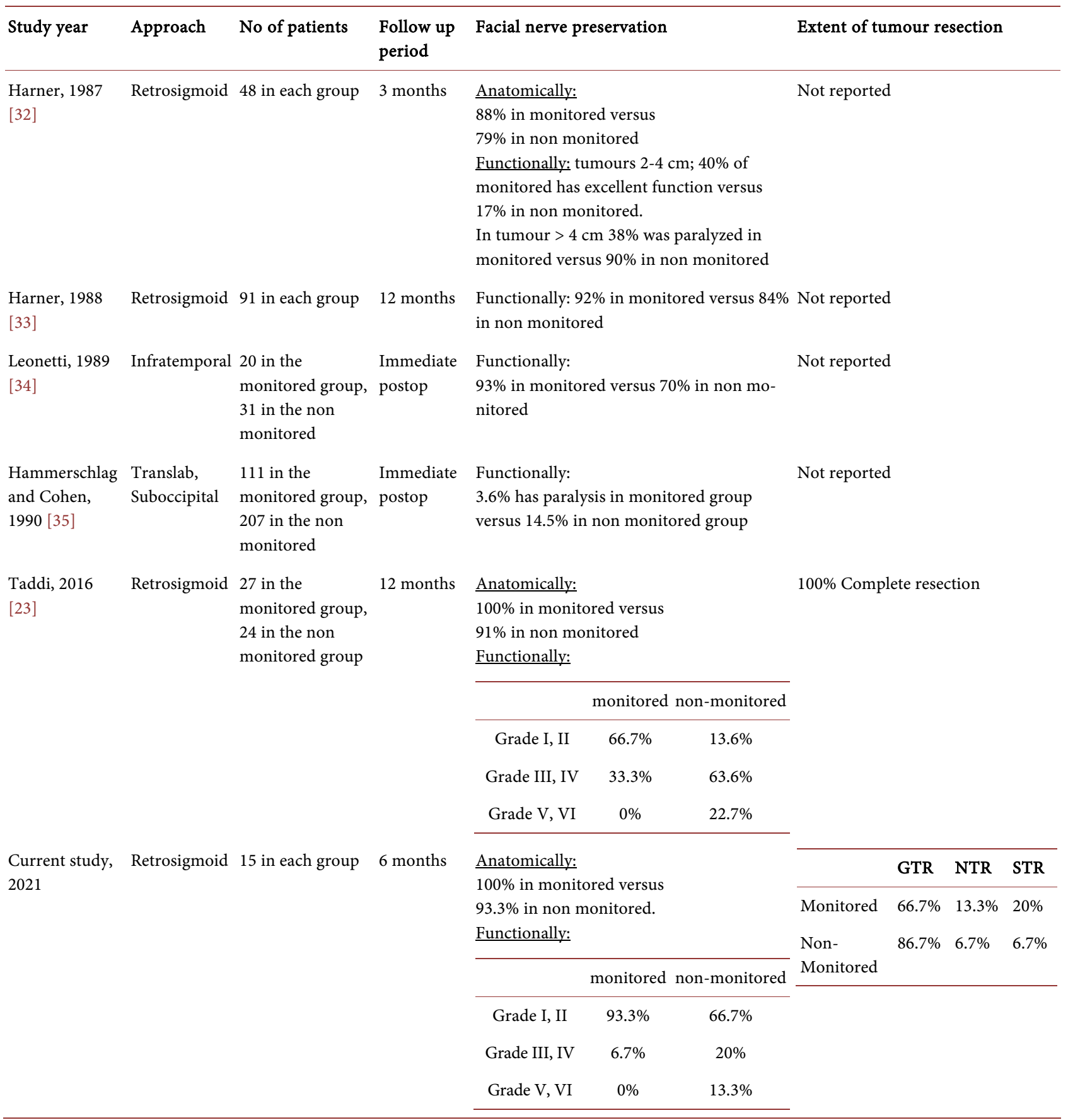

nerve function follow-up and a greater number of patients with long-term MRI follow-up. The short duration of follow-up limits our ability to completely assess final facial nerve function outcome and the long-term consequences of residual tumors.

\section{Conflicts of Interest}

The authors declare no conflicts of interest regarding the publication of this paper. 


\section{References}

[1] Heller, R.S., Silveira, L. and Heilman, C.B. (2018) Cerebellopontine Angle Tumors. Elsevier Inc., Amsterdam. https://doi.org/10.1016/B978-0-323-43140-8.00043-3

[2] Ramsden, R.T. (1995) The Bloody Angle: 100 Years of Acoustic Neuroma Surgery. Journal of the Royal Society of Medicine, 88, 464-468.

[3] Samii, M., Gerganov, V. and Samii, A. (2006) Improved Preservation of Hearing and Facial Nerve Function in Vestibular Schwannoma Surgery via the Retrosigmoid Approach in a Series of 200 Patients. Journal of Neurosurgery, 105, 527-535. https://doi.org/10.3171/jns.2006.105.4.527

[4] Visagan, R., Hall, A., Bradford, R., Khalil, S. and Saeed, S.R. (2019) Is There a Difference in Hospital Stay between Patients Undergoing Translabyrinthine or Retrosigmoid Surgery for Vestibular Schwannoma Stratified by Tumor Size? Journal of Neurological Surgery Part B. Skull Base, 80, 310-315. https://doi.org/10.1055/s-0038-1668541

[5] Jun, W., Gao, Y.L., Yu, H.G., et al. (2020) Comparison of Translabyrinthine and Retrosigmoid Approach for Treating Vestibular Schwannoma: A Meta-Analysis. Clinical Neurology and Neurosurgery, 196, Article ID: 105994. https://doi.org/10.1016/j.clineuro.2020.105994

[6] Huang, X., Xu, M., Xu, J., et al. (2017) Complications and Management of Large Intracranial Vestibular Schwannomas via the Retrosigmoid Approach. World Neurosurgery, 99, 326-335. https://doi.org/10.1016/j.wneu.2016.12.055

[7] Murphy, E.K. (2008) Use of an Infrared Camera to Improve the Outcome of Facial Nerve Monitoring. American Journal of Electroneurodiagnostic Technology, 48, 38-47. https://doi.org/10.1080/1086508X.2008.11079656

[8] Taemin, O., Nagasawa, D.T., Fong, B.M., et al. (2011) Intraoperative Neuromonitoring Techniques in the Surgical Management of Acoustic Neuromas. Neurosurgical Focus, 33, E6. https://doi.org/10.3171/2012.6.FOCUS12194

[9] Fong, B., Barkhoudarian, G., Pezeshkian, P., Parsa, A.T., Gopen, Q. and Yang, I. (2011) The Molecular Biology and Novel Treatments of Vestibular Schwannomas. A Review. Journal of Neurosurgery, 115, 906-914. https://doi.org/10.3171/2011.6.JNS11131

[10] Kalamarides, M., Grayeli, A.B., Fraysse, B., Deguine, O., Favre, G., et al. (2005) Comparison between Intraoperative Observations and Electromyographic Monitoring Data for Facial Nerve Outcome after Vestibular Schwannoma Surgery. Acta OtoLaryngologica, 125, 1069-1074. https://doi.org/10.1080/00016480510038608

[11] Isaacson, B., Kileny, P.R., El-Kashlan, H. and Gadre, A.K. (2003) Intraoperative Monitoring and Facial Nerve Outcomes after Vestibular Schwannoma Resection. Otology \& Neurotology, 24, 812-817. https://doi.org/10.1097/00129492-200309000-00020

[12] Marin, P., Pouliot, D. and Fradet, G. (2011) Facial Nerve Outcome with a Peroperative Stimulation Threshold under 0.05 ma. Laryngoscope, 121, 2295-2298. https://doi.org/10.1002/lary.22359

[13] Noss, R.S., Lalwani, A.K. and Yingling, C.D. (2001) Facial Nerve Monitoring in Middle Ear and Mastoid Surgery. Laryngoscope, 111, 831-836. https://doi.org/10.1097/00005537-200105000-00014

[14] Chen, Z., Prasad, S.C., Di Lella, F., Medina, M., Piccirillo, E., Taibah, A., Russo, A., Yin, S. and Sanna, M. (2014) The Behavior of Residual Tumors and Facial Nerve Outcomes after Incomplete Excision of Vestibular Schwannomas. Journal of Neurosurgery, 120, 1278-1287. https://doi.org/10.3171/2014.2.JNS131497 
[15] Kartush, J.M. (1998) Intra-Operative Monitoring in Acoustic Neuroma Surgery. Neurological Research, 20, 593-596. https://doi.org/10.1080/01616412.1998.11740569

[16] Tatagiba, M. and Acioly, M.A. (2008) Vestibular Schwannoma: Current State of the Art. In: Ramina, R., Pires Aguiar, P.H. and Tatagiba, M., Eds., Samii s Essentials in Neurosurgery, Springer, Stuttgart, 175-188. https://doi.org/10.1007/978-3-540-49250-4 18

[17] Fenton, J.E., Chin, R.Y., Fagan, P.A., Sterkers, O. and Sterkers, J.M. (2002) Predictive Factors of Long-Term Facial Nerve Function after Vestibular Schwannoma Surgery. Otology \& Neurotology, 23, 388-392. https://doi.org/10.1097/00129492-200205000-00027

[18] Zamani, A.A. (2000) Cerebellopontine Angle Tumors: Role of Magnetic Resonance Imaging. Topics in Magnetic Resonance Imaging, 11, 98-107. https://doi.org/10.1097/00002142-200004000-00005

[19] Matthies, C. and Samii, M. (1997) Management of 1000 vs (Acoustic Neuromas): Clinical Presentation. Neurosurgery, 40, 1-10. https://doi.org/10.1227/00006123-199701000-00001

[20] Falcioni, M., Fois, P., Taibah, A. and Sanna, M. (2011) Facial Nerve Function after Vestibular Schwannoma Surgery. Journal of Neurosurgery, 115, 820-826. https://doi.org/10.3171/2011.5.JNS101597

[21] Koos, W.T., Day, D.J., Matula, C. and Levy, D.I. (1998) Neurotopographic Considerations in the Microsurgical Treatment of Small Acoustic Neurinomas. Journal of Neurosurgery, 88, 506-512. https://doi.org/10.3171/jns.1998.88.3.0506

[22] Rinaldi, V., Casale, M., Bressi, F., Potena, M., Vesperini, E., De Franco, A., Silvestri, S., Zini, C. and Salvinelli, F. (2012) Facial Nerve Outcome after Vestibular Schwannoma Surgery: Our Experience. Journal of Neurological Surgery Part B. Skull Base, 73, 21-27. https://doi.org/10.1055/s-0032-1304559

[23] Taddei, G., Marrelli, A., Trovarelli, D., Ricci, A. and Galzio, R.J. (2016) Facial Functional Outcome in Monitored versus Not-Monitored Patients in VS Surgery. Asian Journal of Neurosurgery, 11, 402-406. https://doi.org/10.4103/1793-5482.144208

[24] Youssef, A.S. and Downes, A.E. (2009) Intraoperative Neurophysiological Monitoring in Vestibular Schwannoma Surgery: Advances and Clinical Implications. Neurosurgical Focus, 27, E9. https://doi.org/10.3171/2009.8.FOCUS09144

[25] Bloch, O., Sughrue, M.E., Kaur, R., Kane, A.J., Rutkowski, M.J. and Kaur, G. (2011) Factors Associated with Preservation of Facial Nerve Function after Surgical Resection of Vestibular Schwannoma. Journal of Neuro-Oncology, 102, 281-286. https://doi.org/10.1007/s11060-010-0315-5

[26] Breun, M., Nickl, R., Perez, J., Hagen, R., Löhr, M., Vince, G., Trautner, H., Ernestus, R.I. and Matthies, C. (2019) Vestibular Schwannoma Resection in a Consecutive Series of 502 Cases via the Retrosigmoid Approach: Technical Aspects, Complications, and Functional Outcome. World Neurosurgery, 129, e114-e127. https://doi.org/10.1016/j.wneu.2019.05.056

[27] Jung, S., Kang, S.S., Kim, T.S., Kim, H.J., Jeong, S.K., Kim, S.C., Lee, J.K., Kim, J.H., Kim, S.H. and Lee, J.H. (2000) Current Surgical Results of Retrosigmoid Approach in Extralarge Vestibular Schwannoma. Surgical Neurology, 53, 370-378. https://doi.org/10.1016/S0090-3019(00)00196-8

[28] Anaizi, A.N., Gantwerker, E.A., Pensak, M.L. and Theodosopoulos, P.V. (2014) Facial Nerve Preservation Surgery for Koos Grade 3 and 4 VS. Neurosurgery, 75, 671675. https://doi.org/10.1227/NEU.0000000000000547

[29] Schwartz, M.S., Kari, E., Strickland, B.M., Berliner, K., Brackmann, D.E., House, 
J.W. and Friedman, R.A. (2013) Evaluation of the Increased Use of Partial Resection of Large Vestibular Schwanommas: Facial Nerve Outcomes and Recurrence/Regrowth Rates. Otology \& Neurotology, 34, 1456-1464. https://doi.org/10.1097/MAO.0b013e3182976552

[30] Ferroli, P., Bosio, L. and Broggi, M. (2017) Facial Nerve Sparing Surgery for Large VS. Acta Neurochirurgica (Wien), 159, 1213-1218.

https://doi.org/10.1007/s00701-017-3216-y

[31] Vivas, E.X., Carlson, M.L., Neff, B.A., Shepard, N.T., McCracken, D.J., Sweeney, A.D. and Olson, J.J. (2018) Congress of Neurological Surgeons Systematic Review and Evidence-Based Guidelines on Intraoperative Cranial Nerve Monitoring in Vestibular Schwannoma Surgery. Neurosurgery, 82, E44-E46.

https://doi.org/10.1093/neuros/nyx513

[32] Harner, S.G., Daube, J.R., Ebersold, M.J. and Beatty, C.W. (1987) Improved Preservation of Facial Nerve Function with Use of Electrical Monitoring during Removal of Acoustic Neuromas. Mayo Clinic Proceedings, 62, 92-102. https://doi.org/10.1016/S0025-6196(12)61876-X

[33] Harner, S.G., Daube, J.R., Beatty, C.W. and Ebersold, M.J. (1988) Intraoperative Monitoring of the Facial Nerve. Laryngoscope, 98, 209-212.

https://doi.org/10.1288/00005537-198802000-00018

[34] Leonetti, J.P., Brackmann, D.E. and Prass, R.L. (1989) Improved Preservation of Facial Nerve Function in the Infratemporal Approach to the Skull Base. Otolaryngology-Head and Neck Surgery, 101, 74-78.

https://doi.org/10.1177/019459988910100112

[35] Hammerschlag, P.E. and Cohen, N.L. (1990) Intraoperative Monitoring of Facial Nerve Function in Cerebellopontine Angle Surgery. Otolaryngology_Head and Neck Surgery, 103, 681-684. https://doi.org/10.1177/019459989010300502 